\title{
Development of an immunomagnetic separation-ELISA for the detection of Burkholderia pseudomallei in blood samples
}

\author{
Artitaya Yatsomboon, ${ }^{1,3}$ Rasana W Sermswan, ${ }^{2,3}$ Surasakdi Wongratanacheewin ${ }^{1,3}$
}

\begin{abstract}
Background: Septicemic melioidosis caused by Burkholderia pseudomallei is a serious cause of morbidity and mortality. An effective, rapid and simple diagnostic method is required for detection of B. pseudomallei infection.

Objective: To develop immunomagnetic beads (IMB) coupled with ELISA (IMB-ELISA) for detection of B. pseudomallei in blood samples of patients with suspected melioidosis.

Methods: For separation of B. pseudomallei from buffer, blood samples and hemoculture, 200 nm immunomagnetic beads (IMBs) coated with 4B11 monoclonal antibody (4B11-IMBs) against exopolysaccharide antigens were used. The detection was done by an ELISA based biotin-streptavidin system. The sensitivity and specificity were evaluated.

Results: 4B11-IMBs $(100 \mu \mathrm{g})$ were successfully developed and used for detection of $B$. pseudomallei in $1 \mathrm{ml}$ samples. Transmission electron microscopy (TEM) imaging demonstrated B. pseudomallei was captured by 4B11-IMBs. The IMBs showed high capture efficiency (98\%) with B. pseudomallei in buffer. The IMB-ELISA assay was highly specific for B. pseudomallei. It showed no cross-reactions with other bacteria, except B. mallei. The limits of the B. pseudomallei assay detection for detecting $B$. pseudomallei in either buffer solution or blood was $10^{2} \mathrm{CFU} / \mathrm{ml}$. The IMB-ELISA detection sensitivity in blood samples was $44.5 \%$. Although it did not give the highest sensitivity, it was useful for detection with hemoculture that was faster than conventional methods.
\end{abstract}

Conclusion: This study suggests the IMB-ELISA assay offers a simple and highly specific method with a turnaround time of $6 \mathrm{~h}$ for detection of $B$. pseudomallei. The developed assay can be applied in hospitals for surveillance of $B$. pseudomallei.

Key words: IMB-ELISA, Burkholderia pseudomallei, melioidosis, blood samples, diagnosis

From:

${ }^{1}$ Department of Microbiology,

2 Department of Biochemistry, Faculty of Medicine, Khon Kaen University, Khon Kaen 40002, Thailand;

${ }^{3}$ Melioidosis Research Center, Khon Kaen University, Khon Kaen 40002, Thailand

\section{Introduction}

Melioidosis is a severe disease caused by Burkholderia pseudomallei, which is endemic in Southeast Asia and Northern Australia. It infects via inoculation into wounds, ingestion or inhalation of soil or contaminated water. Northeastern Thailand has reported the highest prevalence. ${ }^{1}$ The diagnosis of melioidosis is difficult due to a variety of signs and symptoms. The laboratory diagnosis of melioidosis still relies on bacterial isolation and identification
Corresponding author:

Surasakdi Wongratanacheewin

Department of Microbiology, Faculty of Medicine,

Khon Kaen University, Khon Kaen, 40002 Thailand

E-mail: sura_wng@kku.ac.th

by biochemical tests using the culture-based method as the gold standard that takes 3 to 7 days, ${ }^{2}$ leading to patient death in some cases. Therefore, a rapid, sensitive, specific and simple diagnostic test is required for detection of the bacterial target, especially in blood samples, for early effective treatment. Many methods have been developed for rapid detection, including antibody, antigen and molecular based methods. 
Indirect hemagglutination (IHA) is the most commonly used method but is not suitable for diagnosis of suspected acute melioidosis in patients in the endemic area. This is because of the high antibody background. ${ }^{3}$ Enzyme-linked immunosorbent assay (ELISA) and related serodiagnostic strategies have been developed for increasing the accuracy for diagnosis using various antigens. The detection of B. pseudomallei antigens in the endemic area have been reported using immunofluorescence assay (IFA) and latex agglutination (LA). The IFA based microscopic assay ${ }^{4}$ can be done in 10 minutes and has been applied for rapid detection of B. pseudomallei in clinical samples. IFA is not suitable for detection of $B$. pseudomallei directly in blood samples because of low numbers of bacteria. ${ }^{5}$ Therefore, it is recommended for detection in the endemic area using an automated blood culture system. ${ }^{6} \mathrm{Al}-$ though MAb-IFA is more rapid than the gold standard method, this assay needs a well-trained person and fluorescence microscope. The LA test is an effective, simple, and inexpensive technique that does not require special instruments for detection of $B$. pseudomallei in clinical samples. The LA assay cannot be used directly in blood samples but needs hemoculture processing before detection. ${ }^{7}$ Lateral flow immunoassay (LFI) has been developed for detection of the capsular polysaccharide (CPS) of B. pseudomallei in clinical samples of patients with active melioidosis using serum, urine, sputum and blood. ${ }^{8}$ The LFI prototype has a limit of detection (LOD) of $0.2 \mathrm{ng} / \mathrm{ml}$ and cannot detect the bacterial target in blood because of low amounts of CPS shedding and bacterial loads in the blood samples. ${ }^{8}$

The immunomagnetic bead (IMB) separation technique is an effective, rapid, specific and simple method that can selectively and specifically bind with the target cells in the sample matrix. The IMB separation technique can be used to concentrate bacterial cells and eliminate unwanted components and substances. ${ }^{9}$ It has been applied to detect targets in the clinical samples. ${ }^{10-12}$ The IMB technique can be successfully designed by using monoclonal antibodies (MAbs) or polyclonal antibodies (PAbs). Many antibodies can be used with this immunologically based method in combination with cultivation or biochemical identification for diagnosis. The combination of IMB with ELISA, or IMB-ELISA method, has been applied for detection of several bacteria, such as Salmonella in milk ${ }^{13}$ and Alicyclobacillus spp. in apple juice. ${ }^{14}$ The turnaround time using the IMB-ELISA method is more rapid than the conventional ELISA method. ${ }^{15}$

In this study, the IMB-ELISA technique was developed using the monoclonal antibody $4 \mathrm{~B} 11$ for detection of B. pseudomallei in blood samples of melioidosis patients suspected of having septicemia. The monoclonal antibody 4B11 against the $200-\mathrm{kDa}$ protein exopolysaccharide (EPS) of B. pseudomallei was successfully used for detection of $B$. pseudomallei..$^{5-7,16-18}$

\section{Methods \\ Blood samples}

Twenty EDTA blood samples ( $1 \mathrm{ml}$ per sample) were obtained from patients who were admitted to the Srinagarind and Khon Kaen Provincial Hospitals. During the period from February 2017 to August 2017, 16 samples were from suspected blood stream infections of B. pseudomallei (BSIs).
In addition, there were four samples suspected to be infected with B. pseudomallei from an epidural abscess, sputum (2) and pus from a wound. The EDTA blood samples were obtained on the same or nearest day of admission and sent for the hemoculture procedure. The EDTA blood samples from healthy donors were used as the negative controls. The protocol was approved by the Human Research Ethics Committee of Khon Kaen University and Khon Kaen Hospitals, Thailand (HE591440 and KE60065). All samples were taken from leftover specimens; thus, the gathering of consents was not possible.

\section{Antibodies and magnetic bead particles}

The 4B11 monoclonal antibody (isotype IgG2a) against the $200-\mathrm{kDa}$ EPS presented on the surface of all B. pseudomallei isolates was used. ${ }^{18,19}$ The 4B11 hybridoma cells were kindly provided by Prof. Stitaya Sirisinha, Mahidol University, Bangkok, Thailand. Polyclonal antibodies derived from rabbit antibodies against whole $B$. pseudomallei cells (crude extracted antigen of $B$. pseudomallei) were raised and used throughout this study. The animal protocol was approved by the Animal Research Ethics Committee of Khon Kaen University (AEKKU15/2555). Four different kinds of magnetic bead particles, including SiMAG-Cyanuric (C500) with the size of $500 \mathrm{~nm}$, FluidMAG-Amine (F200) with the size of $200 \mathrm{~nm}$ and 2 sizes of SiMAG-Amine S500 (500 nm) and S750 (750 nm), were used in this study. All magnetic beads that were synthesized from $\mathrm{Fe}_{3} \mathrm{O}_{4}$ or iron oxide (ferric oxide) were purchased from Chemicell GmbH, Germany. The magnetic bead set-up and optimization process showed that F200 (200 nm) was the best bead for detection of B. pseudomallei and only the F200 beads were used throughout this study.

\section{Coating of antibody on fluid-amine beads}

\section{4B11 monoclonal antibody preparation}

The hybridoma cells were grew in RPMI medium supplemented with $20 \%$ FBS, $0.4 \% 10 \mathrm{mg}$ gentamicin, and $0.5 \%$ $0.01 \mathrm{M}$ mercaptoethanol in IMDM and cultured in $5 \% \mathrm{CO}_{2}$. The supernatants containing the antibody were concentrated and purified by ammonium sulfate and desalted and purified by HiTrap ${ }^{\mathrm{TM}}$ Desalting and HiTrap ${ }^{\mathrm{TM}}$ Protein G column (GE Healthcare, UK).

\section{Antibody coated on magnetic beads for producing 4B11-IMB}

The F200 beads were coated to produce IMB by the covalent coupling procedure (carbodiimide method), according to the manufacturer's instructions with some modifications..$^{20}$ In this study, 4B11-IMB and uncoated-IMB represent the beads coated with 4B11 Mab and uncoated beads. Firstly, $1 \mathrm{mg}$ F200 particles were washed twice with $1 \mathrm{ml}$ MES buffer $(0.1$ M 2-(N-Morpholino) ethanesulfonic acid, pH 6.0) (Merck, Germany) prior to re-suspension in $0.25 \mathrm{ml}$ MES buffer containing $10 \mathrm{mg}$ fresh EDC (1-ethyl-3-(3-dimethylaminopropyl) carbodiimide) (Pierce, USA). The monoclonal antibodies at $0,10,50,100,120 \mu \mathrm{g} / \mathrm{ml}$ were added for titration of concentrations to coat the beads and mixed for $2 \mathrm{~h}$. Bovine serum albumin (BSA) (2\%) in PBS (0.01 M pH 7.4) with $0.05 \%$ $\mathrm{NaN}_{3}$ was added for protection against non-specific reactions. 
The concentration of BSA $(0.1 \%-8 \%)$ in the blocking buffer was optimized before use. The optimal concentration of BSA for blocking giving lowest background was $2 \%$ for $30 \mathrm{~min}$ utes. The particles were washed 3 times and stored at $4^{\circ} \mathrm{C}$ until used. The efficiency of bead coating was determined by direct detection of antibody on beads by ELISA and measurement of unbound antibody in the buffer by NanoDrop 2000 spectrophotometry (Thermo Fisher Scientific Inc., Wilmington, USA). The capture efficiency (CE) of 4B11-IMB against B. pseudomallei was evaluated using the formula as follows: $\mathrm{CE}=(1-\mathrm{B} / \mathrm{A}) \times 100 \%)$, where $\mathrm{A}$ is the total number of cells present in the sample $(\mathrm{CFU} / \mathrm{ml})$ and $B$ is the number of cells unbound to $\mathrm{IMBs}(\mathrm{CFU} / \mathrm{ml})$ in the supernatant and wash solutions. $^{25}$ Then, $100 \mu \mathrm{g}$ 4B11-IMB was added in $1 \mathrm{ml}$ PBS containing B. pseudomallei at $10^{7}, 10^{6}, 10^{5}, 10^{4}, 10^{3}$, and $10^{2}$ $\mathrm{CFU} / \mathrm{ml}$ to capture cells. The uncoated-IMB captured B. pseudomallei at $10^{5} \mathrm{CFU} / \mathrm{ml}$ acting as a negative control. The irrelevant antibody coated-IMBs were also used as a negative control and a low background was obtained. The total number of B. pseudomallei were enumerated before capture by 4B11-IMB and after $1 \mathrm{~h}$ incubation. The unbound bacterial cells in the supernatant and washed buffer were enumerated by the drop plate assay method (incubation of NA plates at $37^{\circ} \mathrm{C}$ for $18 \mathrm{~h}$ ). All experiments were performed in triplicate. The binding between 4B11-IMB and B. pseudomallei was confirmed by using transmission electron microscopy (TEM) (FEI, TECNAI G ${ }^{2}$, Hillsboro, Oregon, USA).

\section{IMB-ELISA in buffer and spiking blood samples}

To develop a specific, sensitive and suitable IMB-ELISA, various substances in the ELISA assay were titrated against $10^{5} \mathrm{CFU} / \mathrm{ml} \mathrm{B}$. pseudomallei cells, including dilutions of PAbs at $1: 250$ to $1: 6000$ as the detection antibodies, prior to being detected by biotinylated anti-rabbit IgG (Goat anti-Rabbit IgG $(\mathrm{H}+\mathrm{L})$ (Thermo Fisher Scientific Inc., Rockford, USA) at $1: 10,000$ to $1: 50,000$, and streptavidin-HRP (Streptavidin, Horseradish Peroxidase Conjugate, Merck KGaA, Darmstadt, Germany) at $1: 4,000$ to $1: 20,000$. The optimal ratio of PAb was $1: 3,000$ and $1: 12,000$ for biotinylated anti-rabbit IgG and 1:10,000 for streptavidin-HRP.

The IMB-ELISA was tested for detection of B. pseudomallei in buffer and spiked blood samples. B. pseudomallei was diluted to $10^{5} \mathrm{CFU} / \mathrm{ml}$ in $1 \mathrm{ml} \mathrm{PBS}$; meanwhile, the fresh whole blood obtained from a registered blood bank was spiked. A schematic illustration of the system for detection of B. pseudomallei by IMB-ELISA is shown in Figure 1. The 100 $\mu \mathrm{g}$ 4B11-IMBs were added into buffer in microtubes containing of $B$. pseudomallei then mixed for $1 \mathrm{~h}$. The 4B11-IMB bacterial complexes were captured and precipitated at the sides of the microtubes when placed on a magnetic separator for 5 minutes and the supernatants were removed. The reaction tubes were washed and $200 \mu \mathrm{l}$ 1:3,000 PAb was added in the reaction tubes and incubated for 30 minutes. The supernatants that contained unbound PAb were removed and washed, and $200 \mu \mathrm{l}$ 1:12,000 biotinylated anti-rabbit IgG was added
A

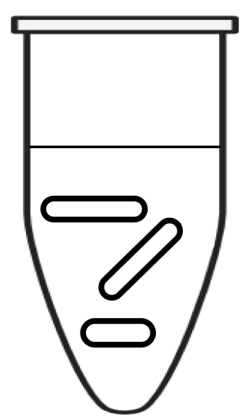

D

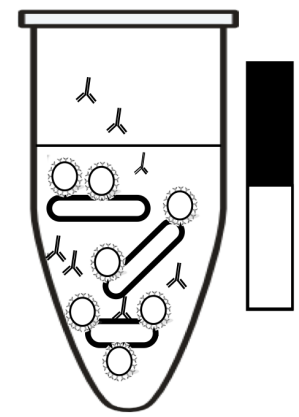

B

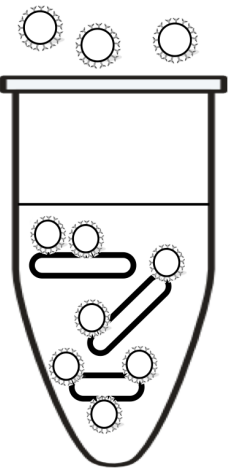

$\mathbf{E}$

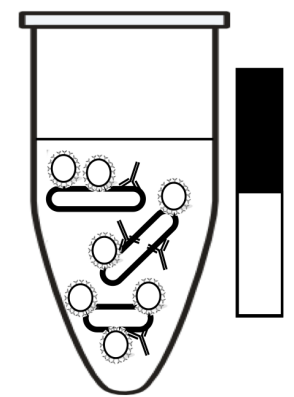

C

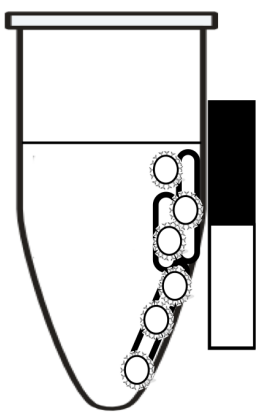

F

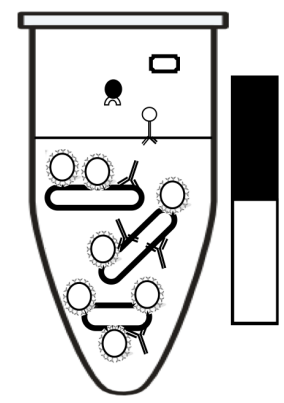

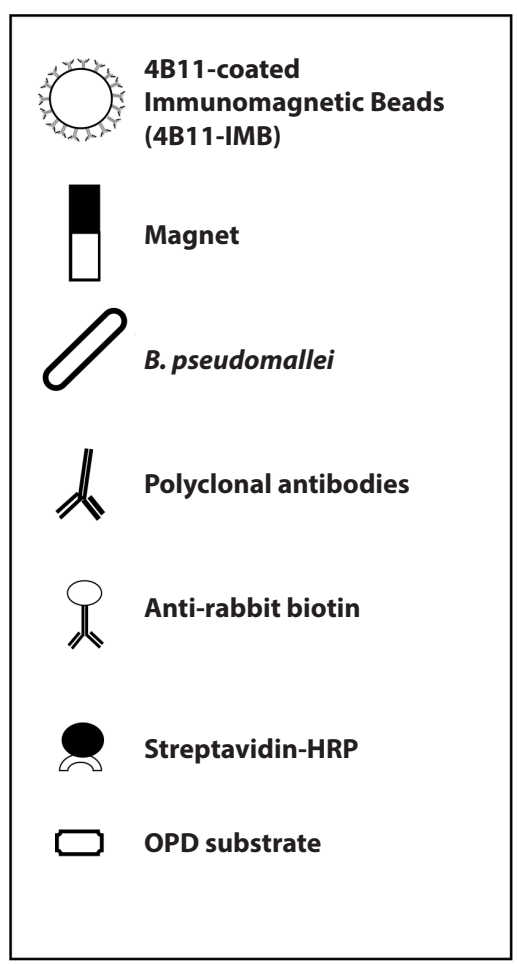

Figure 1. Schematic illustration of the system for detection of Burkholderia pseudomallei by IMB-ELISA. Bacteria in $1 \mathrm{ml}$ of blood samples in microtubes (A) were captured by 4B11-IMB (B). After incubation for $1 \mathrm{~h}$, the bacteria-bound beads were separated by magnetic force $(\mathrm{C})$ and the unbound substances were removed from the reaction. The secondary (PAb) against $B$. pseudomallei were then added and incubated for $30 \mathrm{~min}$ (D) followed by removing the excess antibodies (E). The conjugated antibodies (biotinylated anti-rabbit antibodies and streptavidin-HRP) were added (F) for detection by ELISA. 
and incubated for 30 minutes. The unbound conjugate was removed and this was followed by washing 3 times, then 200 $\mu \mathrm{l}$ of $1: 10,000$ streptavidin-HRP in $2 \%$ BSA in $0.01 \mathrm{M} \mathrm{pH} 7.4$ PBS with $0.05 \%$ Tween 20 was added, mixed and incubated for 30 minutes at room temperature (RT). After washing, 100 $\mu$ l OPD (1,2-phenylenediamine dihydrochloride; Dako) substrate was added. The end product was transferred into a 96 well plate (Nunc, Roskilde, Denmark), and the absorbance measurement was carried out at $492 \mathrm{~nm}$ with the ELISA reader (TECAN Infinite 200, Tecan Group Ltd, San Jose, USA).

\section{IMB-ELISA for detection of B. pseudomallei in hemoculture}

B. pseudomallei at concentrations of $10^{3}, 10^{2}$, and $10^{1} \mathrm{CFU} /$ $\mathrm{ml}$ were spiked into $5 \mathrm{ml}$ fresh blood and then injected into blood culture bottles that contained $45 \mathrm{ml}$ of hemoculture media (Liquid broth, Himedia, India). The hemoculture bottles were incubated at $37^{\circ} \mathrm{C}$. The tests were performed in triplicate for each bacterial concentration. After culture for 0,5 , $10,15,24$ and $48 \mathrm{~h}, 100 \mu \mathrm{l}$ of each sample from the hemoculture bottles were taken for either culture with biochemical identification or with IMB-ELISA for comparison. The times required for positive detection and identification were then compared.

\section{Specificity and sensitivity of IMB-ELISA}

For the specificity testing, S. aureus, E. coli, B. mallei, B. cepacia, B. thailandensis and P. aeruginosa were cultured in LB at $37^{\circ} \mathrm{C}$ to mid-log phase and diluted to $10^{5} \mathrm{CFU} / \mathrm{ml}$ in buffer. For the sensitivity testing, B. pseudomallei were serially diluted in PBS buffer from $10^{0}$ to $10^{7} \mathrm{CFU} / \mathrm{ml}$ and used to determine the sensitivity of IMB-ELISA in buffer and spiked blood samples. The bacterial dilutions of $100 \mu \mathrm{l}$ containing concentrations of $10^{7}, 10^{6}, 10^{5}, 10^{4}, 10^{3}, 10^{2}, 10^{1}$ and $10^{0} \mathrm{CFU} / \mathrm{ml}$ were placed into $900 \mu \mathrm{l}$ of buffer and fresh EDTA blood samples of healthy persons. The detection procedure was the same as the IMB-ELISA.

\section{A}

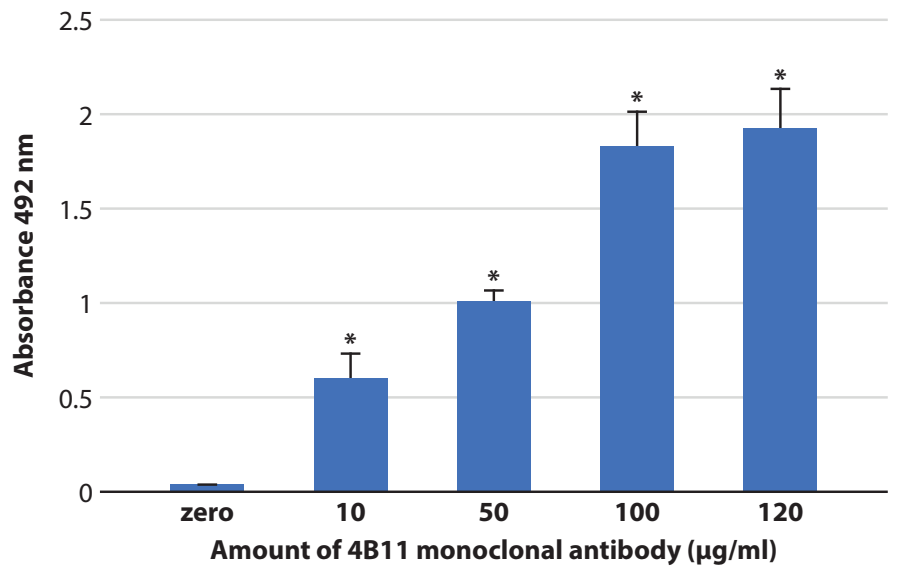

\section{Sample tests}

The samples of EDTA blood $(1 \mathrm{ml})$ were tested by using the same procedures as with IMB-ELISA in the buffer and blood samples as previously mentioned.

\section{Statistical analysis}

The statistical methods that were used in this study included the t-test, paired t-test, and one-way analysis of variance (ANOVA) for comparisons. Data were analyzed by using the $\mathrm{IMB}^{\circ} \mathrm{SPSS}^{\circ}$ version 23. All data were presented as mean values with their standard deviations (mean \pm SD). The cut-off line of IMB-ELISA could be calculated by using the mean of absorbance of the negative control plus three SD (Background Cut-off $=$ Mean of Negatives $+[3$ SD of Negatives $])$. The OD of the negative control was obtained from detection of 4B11IMB in the blood without bacteria. Therefore, the cut-off value was 0.52 .

\section{Results \\ Optimization and efficiency of antibody for producing 4B11- $I M B$}

The Fluid-MAG (F200) showed an optimum value when used with the ELISA for detection of B. pseudomallei. The concentrations of MAb coated on beads were detected by ELI$\mathrm{SA}$ and the results are shown in Figure 2A. Results demonstrated that the optimal concentrations of MAb coated on the beads were $100 \mu \mathrm{g} / \mathrm{ml}$ and $120 \mu \mathrm{g} / \mathrm{ml}$; however, only the MAb at $120 \mu \mathrm{g} / \mathrm{ml}$ was selected. The coating efficiency was determined and the results shown in Figure 2B demonstrate that most antibodies used for coating are significantly bound on the beads. The results demonstrated that the optimal 4B11IMB concentrations could bind nearly $100 \%$ of all bacteria ( $98 \%$ of $\mathrm{CE}$ at $3 \times 10^{2}$ cells, Figure $2 \mathrm{C}$ ). In contrast, when the higher numbers of bacteria were used, lower efficiency was obtained. The 4B11-IMB-bound B. pseudomallei in buffer and the negative control beads are shown in the TEM photograph in Figures 2D and 2E, respectively.

\section{B}

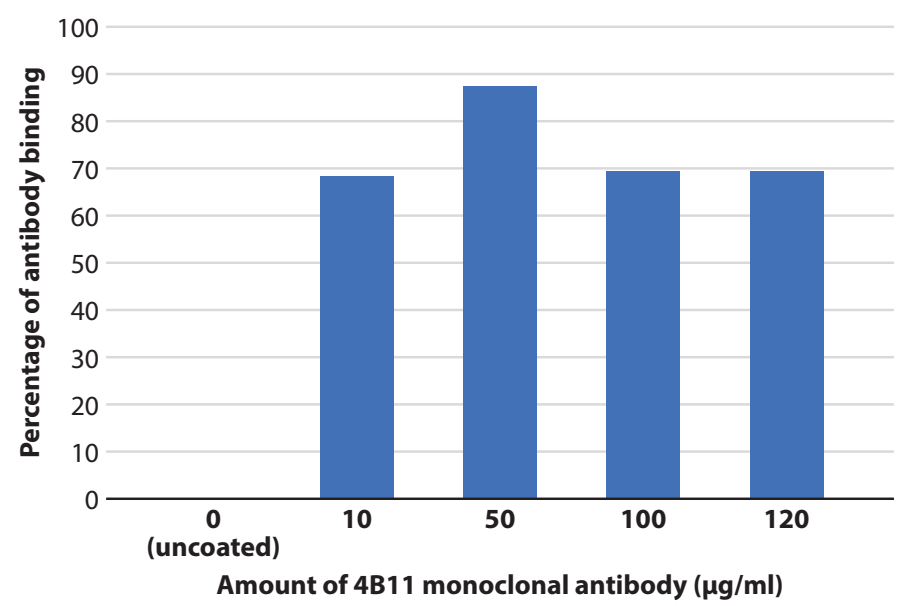

Figure 2. The optimization of coating antibodies for MAb-coated IMB. The various concentrations of $0,10,50,100$ and 120 $\mu \mathrm{g} / \mathrm{ml}$ of monoclonal antibody $4 \mathrm{~B} 11$ were coated on beads and concentrations of bound antibodies were determined by ELISA (A). Each bar represents mean \pm SD of the absorbance of antibody coated on the beads. The asterisks $\left.{ }^{*}\right)$ indicate statistical significance $(p<0.05)$ compare to control. The percentage of antibody binding was calculated by the percent of the amount of antibody added minus the amount of antibody left divided by the amount of antibody added (B). 

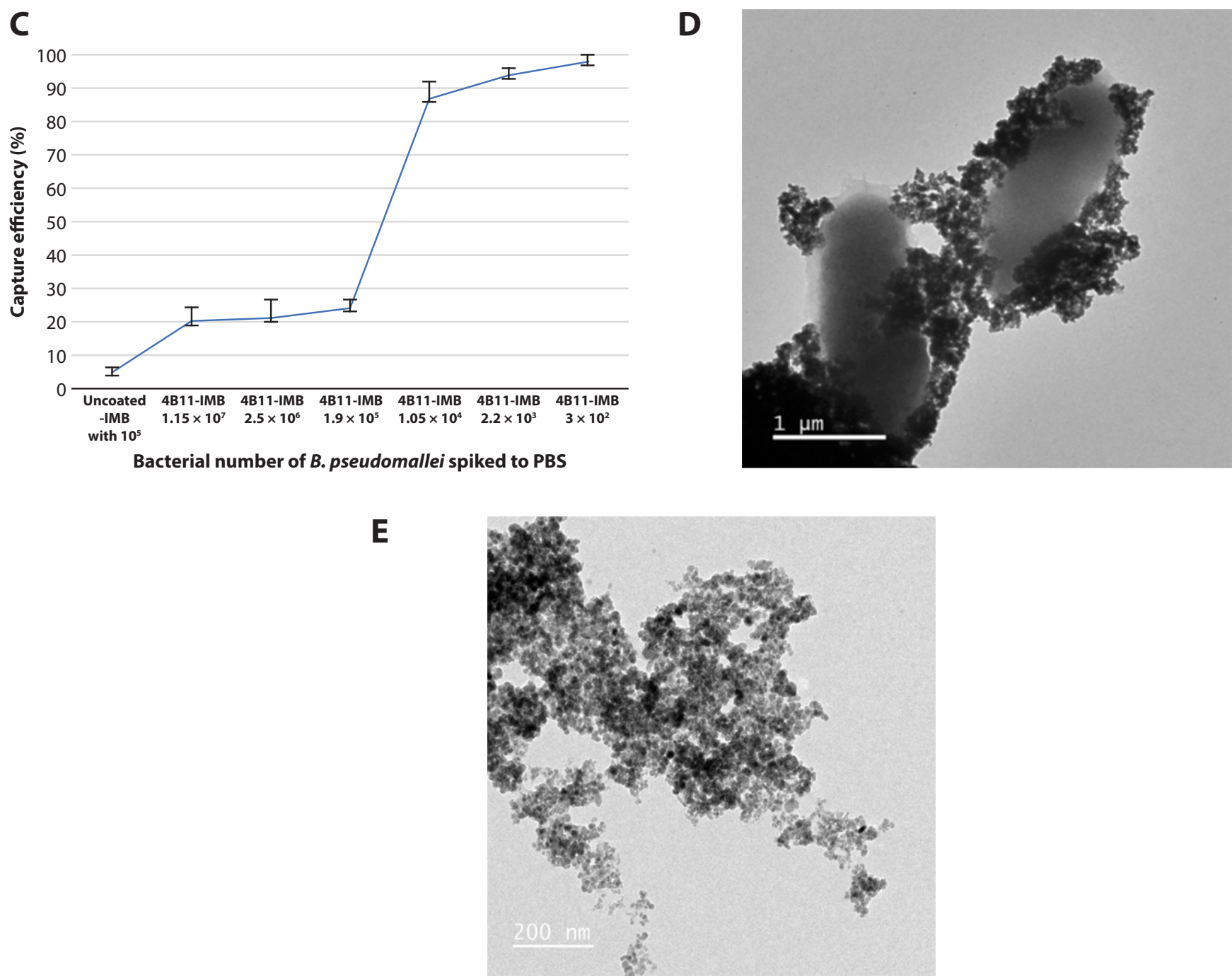

Figure 2. (Continued) The optimal coated-IMB (4B11-IMB) were evaluated for capture efficiency using $3 \times 10^{2}, 2.2 \times 10^{3}, 1.05$ $\times 10^{4}, 1.9 \times 10^{5}, 2.5 \times 10^{6}, 1.15 \times 10^{7} \mathrm{~B}$. pseudomallei cells $(\mathrm{C})$. The bound and unbound bacteria were measured by the culture method and the percentage of capture efficiency (CE) calculated to evaluate the ability of the bead for binding, capture and separation of bacteria. The line represents the mean of $\mathrm{CE} \pm \mathrm{SD}$. The uncoated-IMB used for capturing $B$. pseudomallei at $10^{5} \mathrm{CFU} /$ $\mathrm{ml}$ was used as a negative control. TEM image of the F200 IMB-bound B. pseudomallei in buffer (PBS) (D). The negative control beads are shown (E).

\section{Specificity and sensitivity of IMB-ELISA}

For specificity testing, various bacteria including $B$. pseudomallei, P. aeruginosa, B. mallei, B. cepacia, B. thailandensis, $E$. coli and $S$. aureus were placed at $10^{5} \mathrm{CFU} / \mathrm{ml}$ into $1 \mathrm{ml}$ of buffer and then detected by IMB-ELISA. The results demonstrated that this method gave a negative response in all other bacteria tested with high specificity for $B$. pseudomallei and B. mallei (Figure 3A), although E. coli gave more background than others. Our result demonstrated that the bacteria at $10^{2}$ $\mathrm{CFU} / \mathrm{mL}$ was the lowest dilution that registered an $\mathrm{OD}>0.52$. The sensitivity for detection in the buffer and spiked blood samples was $10^{2} \mathrm{CFU} / \mathrm{ml}$ (Figure 3B).

\section{Detection of B. pseudomallei in blood samples}

Thirteen $1 \mathrm{ml}$ EDTA blood samples were tested by IMBELISA. The samples were positive in $4 / 20$ samples for IMBELISA (Table 1). Out of 20 samples, 16 samples were suspected blood stream infections (BSIs) with B. pseudomallei and four samples were infected with B. pseudomallei from other sources. A total of 9 out of 16 of the BSIs were confirmed positive by hemoculture; 7 were negative by hemoculture. There were four positives with IMB-ELISA, which correlated with hemoculture positive results. Therefore, the sensitivity of IMB-ELISA was $44.5 \%$ (4/9) when comparing positive cultures. 
A

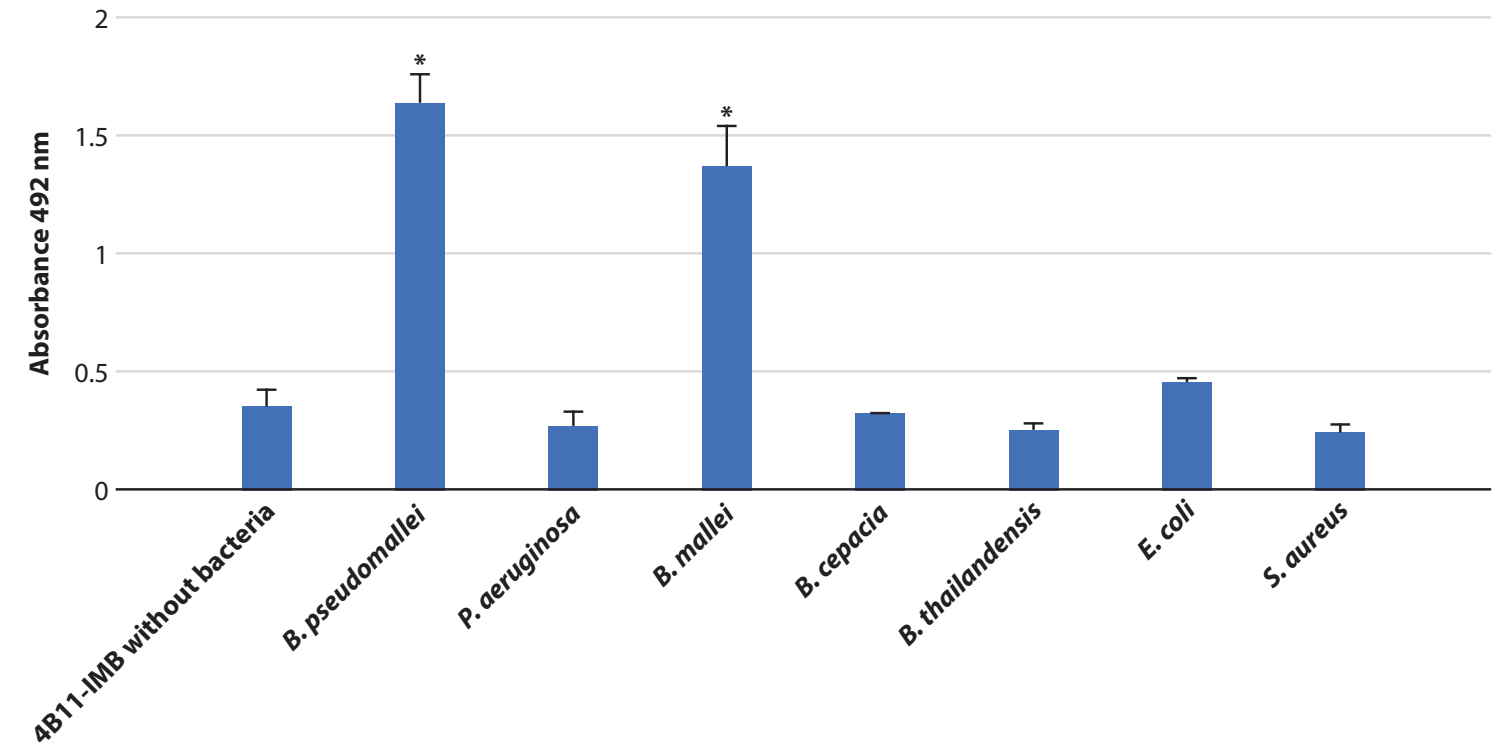

B

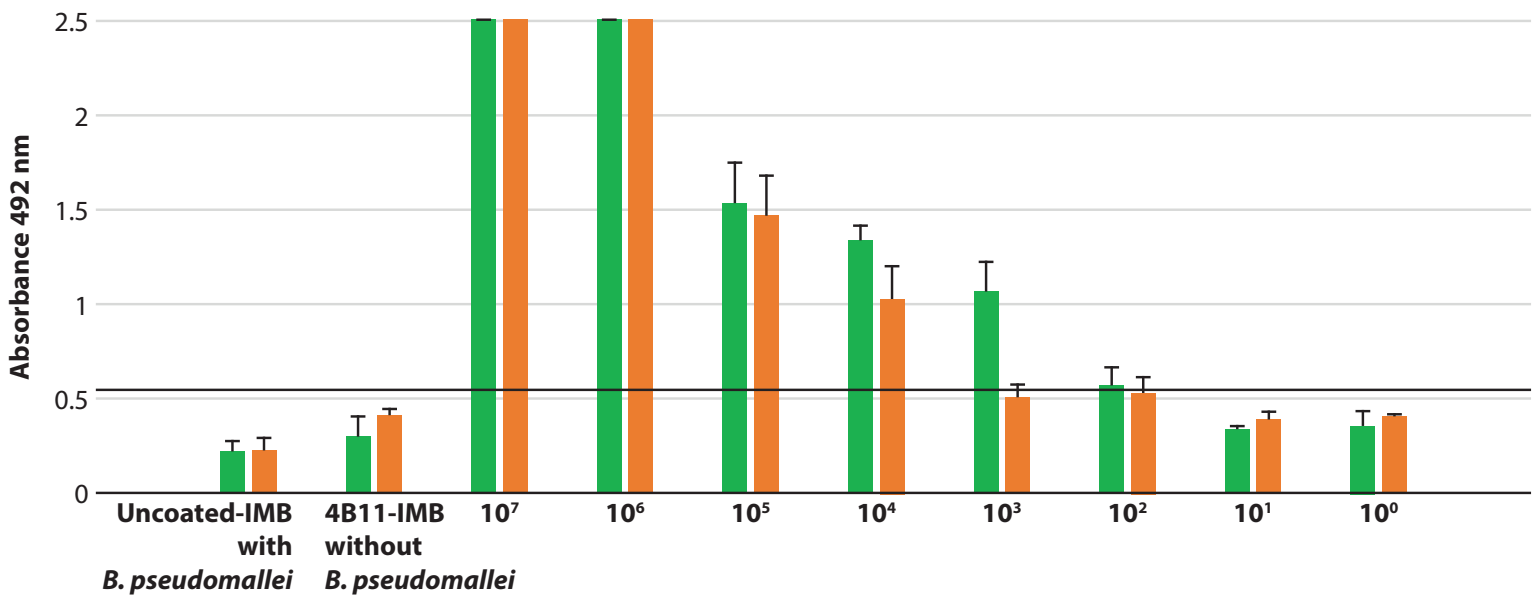

Concentration of B. pseudomallei (CFU/ml)

PBS

Blood

Figure 3. Specificity and sensitivity of IMB-ELISA for detection of $\boldsymbol{B}$. pseudomallei. For the specificity test, $10^{5} \mathrm{CFU} / \mathrm{ml}$ of various bacteria were spiked into $1 \mathrm{ml}$ EDTA blood and detected by IMB-ELISA while the 4B11-IMB without bacteria was used as the negative control (A). Each bar represents mean \pm SD. The asterisks $\left(^{*}\right)$ indicate statistical significance $(\mathrm{p}<0.05)$ compare to control. Sensitivity of IMB-ELISA was tested for detection of B. pseudomallei in buffer compared with inoculated blood samples (B). The B. pseudomallei was 10 -fold serially diluted from $10^{0}$ to $10^{7} \mathrm{CFU} / \mathrm{ml}$ into $1 \mathrm{ml}$ of PBS buffer and EDTA blood prior for detection by using IMB-ELISA. The negative control groups included uncoated-IMB with $10^{5} \mathrm{CFU} / \mathrm{ml}$ of $\mathrm{B}$. pseudomallei and 4B11-IMB without bacteria. The absorbance by the ELISA reader was at $492 \mathrm{~nm}$. Each bar represents mean \pm SD. The line represents the cut off (Mean of 4B11-IMB without bacteria plus $3 \mathrm{SD}$ ) of the IMB-ELISA test. 
Table 1. Detection of B. pseudomallei in the blood samples of suspected melioidosis patients by hemoculture and IMB-ELISA

\begin{tabular}{|c|c|c|c|c|c|}
\hline \multirow{2}{*}{ Sample number } & \multirow{2}{*}{ Specimen sites ${ }^{\star}$} & \multicolumn{2}{|c|}{ Method for detections } & \multicolumn{2}{|c|}{ Detection date } \\
\hline & & Hemoculture & IMB-ELISA/OD value & Hemoculture & IMB-ELISA \\
\hline 1 & Blood & + & $+/ 0.623$ & 28-Feb-17 & 2-Mar-17 \\
\hline 2 & Blood & + & $-/ 0.407$ & 12-Mar-17 & 14-Mar-17 \\
\hline 3 & Blood & + & $-/ 0.393$ & 10-Mar-17 & 13-Mar-17 \\
\hline 4 & Blood & + & $-/ 0.412$ & 17-Mar-17 & 20-Mar-17 \\
\hline 5 & Epidural abscess ${ }^{*}$ & ND & $-/ 0.341$ & ND & 22-Mar-17 \\
\hline 6 & Sputum ${ }^{\star}$ & ND & $-/ 0.320$ & ND & 3-Apr-17 \\
\hline 7 & Sputum* & ND & $-/ 0.251$ & ND & 3-Apr-17 \\
\hline 8 & Blood & No growth & $-/ 0.311$ & 15-May-17 & 15-May-17 \\
\hline 9 & Blood & + & $+/ 0.801$ & 31-May-17 & 31-May-17 \\
\hline 10 & Blood & No growth & $-/ 0.315$ & 21-Jun-17 & 21-Jun-17 \\
\hline 11 & Pus from wound ${ }^{*}$ & ND & $-/ 0.382$ & ND & 28-Jun-17 \\
\hline 12 & Blood & + & $+/ 0.790$ & 4-Jul-17 & 4-Jul-17 \\
\hline 13 & Blood & + & $-/ 0.434$ & 16-Aug-17 & 16-Aug-17 \\
\hline 14 & Blood & No growth & $-/ 0.295$ & 3-May-17 & 16-May-17 \\
\hline 15 & Blood & No growth & $-/ 0.377$ & 7-Apr-17 & 17-Apr-17 \\
\hline 16 & Blood & No growth & $-/ 0.311$ & 9-May-17 & 18-May-17 \\
\hline 17 & Blood & No growth & $-/ 0.380$ & 7-Aug-17 & 9-Aug-17 \\
\hline 18 & Blood & No growth & $-/ 0.295$ & 14-Aug-17 & 18-Aug-17 \\
\hline 19 & Blood & + & $+/ 0.550$ & 10-June-17 & 12-June-17 \\
\hline 20 & Blood & + & $-/ 0.424$ & 13-June-17 & 13-June-17 \\
\hline
\end{tabular}

- Negative for the IMB-ELISA

+ Positive for the test (positive B. pseudomallei for hemoculture and positive IMB ELISA test)

ND: not determined by hemoculture

* Blood from patients with other specimen suspected to have local melioidosis were used as negative control

\section{Comparison of the detection by hemoculture against IMB-ELISA}

As the developed method could not reach a high sensitivity, clinical blood samples, therefore, would have to be cultured to enrich the bacteria before detection. Comparisons of the time required for detection by hemoculture and IMB-ELISA were then performed (Table 2). The results found that the positive culture could be detected at $15 \mathrm{~h}$ when the hemocultures were spiked at $10^{1}$ and $10^{2} \mathrm{CFU} / \mathrm{ml}$, while at $10^{3} \mathrm{CFU} / \mathrm{ml}$, it could be found at the beginning $(0 \mathrm{~h})$. When the positive colonies were used to identify biochemical tests, another $36 \mathrm{~h}$ was required before the final results were obtained, whereas the IMB-ELISA method needed only $6 \mathrm{~h}$. The summary of times used for positive identification results are shown in Table 2. The results demonstrated that although the IMB-ELISA method gave low sensitivity by itself, when used with the culture method, it gave faster results than using culture with biochemical tests.
Table 2. Comparison of the time required for positive detections by hemoculture and IMB-ELISA

\begin{tabular}{|c|c|c|}
\hline \multirow{2}{*}{$\begin{array}{l}\text { Concentration of } \\
\text { initial bacteria in } \\
\text { spiked blood culture } \\
(\mathrm{CFU} / \mathrm{ml})\end{array}$} & \multicolumn{2}{|c|}{ Time (hrs) used for positive detections by } \\
\hline & $\begin{array}{c}\text { Hemoculture } \\
\text { (with biochemical } \\
\text { identifications) }\end{array}$ & IMB-ELISA \\
\hline 0 & $\mathrm{NG}^{*}$ & $\mathrm{NG}^{*}$ \\
\hline $10^{1}$ & 51 & 21 \\
\hline $10^{2}$ & 51 & 21 \\
\hline $10^{3}$ & 36 & 11 \\
\hline
\end{tabular}

${ }^{\star}$ No growth (negative control) 


\section{Discussion}

Culture is still the gold standard for detection, especially when patients are suspected of having BSIs with B. pseudomallei. It is time-consuming ( 3 to 7 days) and most often the results are obtained after the patients have died. ${ }^{1}$ Therefore, many alternative methods have been developed for rapid detection, including antibody, antigen and molecular based detection. The antibody method has problems because of a high antibody background in the endemic area. ${ }^{21,22}$ The antigen detection gives more advantages but still has low sensitivity when used for detection in direct blood samples because of the low number of bacterial cells in the blood. LFI could be used for detection in serum, urine, and sputum but not in the blood because of the low CPS shedding and bacterial loads in the blood sample. ${ }^{8}$ Nevertheless, after LFI was optimized, it was evaluated by detection of $B$. pseudomallei in EDTA blood samples of acutely septic patients with a sensitivity of $40 \%,{ }^{23}$ with accuracy for detection of $B$. pseudomallei in hemoculture broth (BacT/Alert, bioMérieux, Marcy L'Etoile, France). ${ }^{24}$

The examples for using IMB separation for improving the problem of detection are Francisella tularensis and Yersinia pestis, which are slow growth bacteria and difficult to diagnose. ${ }^{10}$ IMB-ELISA was applied for detection of several bacteria, such as Salmonella in milk with a LOD of $10^{5}-10^{6} \mathrm{CFU} /$ $\mathrm{mL},{ }^{13} \mathrm{~S}$. aureus with a LOD of $1 \mathrm{ng}\left(10^{5}\right.$ cells per $\left.\mathrm{ml}\right){ }^{25}$ and Alicyclobacillus spp. in apple juice with a LOD of $10^{3} \mathrm{CFU} /$ $\mathrm{mL} .{ }^{14}$ The present IMB-ELISA assay gave a LOD of the bacteria in the buffer of $10^{2} \mathrm{CFU} / \mathrm{ml}$, which is much better than other IMB-ELISAs reported and it is the first report for detection of B. pseudomallei in blood samples. The ELISA was combined with IMB, because it is an easy method that is suitable for use in hospitals in the endemic area. The F200 was used because it showed a lower background and a higher signal for detection than other beads (C500, S500 and S750). Moreover, the F200 beads had the maximum surface area $\left(2.77 \times 10^{16} \mathrm{~nm}^{2}\right)$ followed by S500 $\left(1.18 \times 10^{16} \mathrm{~nm}^{2}\right)$ and S750 $\left(7.4 \times 10^{15} \mathrm{~nm}^{2}\right)$. As these findings correlated with other publications that showed the larger beads have low capture and separation efficiencies, while smaller nanobeads were more effective for binding with bacterial surfaces in food samples. ${ }^{26}$ The small beads contain faster reaction kinetics, lower mass, higher surface to volume ratios and multiple sites for binding of the target cells to the surface. ${ }^{27}$

While specificity was a concern (Figure 3A), 4B11-IMB showed specificity with $B$. pseudomallei, although there were minor cross-reactions with E. coli. This MAb had been reported to bind only with B. pseudomallei and B. mallei. The 4B11MAb IgG2b subclass against the 200-kDa EPS of B. pseudomallei is widely used in agglutination for identification of $B$. pseudomallei. This 4B11-MAb could also be used to differentiate between $B$. pseudomallei and B. thailandensis, which are closely related bacteria.

The reason why cross-reactions occurred with other bacteria tested is unknown. It was hypothesized that this might be due to the non-specific binding of the cross-reactive bacteria to the beads. The absorbance of $B$. mallei was nearly similar to $B$. pseudomallei, as these 2 strains are related with a $99 \%$ similarity of their genomes $(9,10)$. B. mallei, however, is not zoonotic and has never been reported in humans. ${ }^{28}$
The other possible non-specific background might be due to the interaction between immobilized 4B11-MAb and polyclonal rabbits and/or anti-rabbits. However, we evaluated such a possibility by ELISA. The 4B11-MAb was coated onto the 96 well plates followed by polyclonal rabbits and/or anti-rabbits. The results found no reaction between them $(\mathrm{OD}<0.1)$.

The sensitivity of optimized IMB-ELISA (Figure 3B) was $10^{2} \mathrm{CFU} / \mathrm{ml}$. The CE of the beads, however, was found to be nearly $100 \%$ (Figure 2B) when $10^{2} \mathrm{CFU} / \mathrm{ml}$ bacteria were available. Therefore, the lower sensitivity might be due to the ELISA system and not the capture ability of the coated beads. Another possible factor leading to low sensitivity is the 4B11 reactive epitope, the EPS antigen. It could be shedding from the cells into the media or clinical samples. ${ }^{16}$ The antigen concentrations might be varied in different specimens. When the time required for getting the results was compared between hemoculture and IMB-ELISA (Table 2), the results found that the sensitivity of the culture was higher than IMB-ELISA. Additionally, the times for identification by the biochemical tests were long, whereas the IMB-ELISA took only $6 \mathrm{~h}$ after sufficient growth of the bacteria. Only three positives of the IMB-ELISA were correlated with positive hemocultures. The possible reasons for low sensitivity were: 1) only $1 \mathrm{ml}$ of samples were used for detection and 2) the samples were not from the same time as the hemoculture (they were EDTA blood samples taken 1-2 days after). Moreover, further development of the IMB system combined with other methods, such as Quantum dot, may increase sensitivity. ${ }^{12}$ Quantum dots (QDs) are the new fluorescent markers or class of fluorophores or autofluorescence, which increase fluorescence intensities, long-term photostability and can be excited by a wide spectrum of wavelengths. ${ }^{29}$ IMB-QD was used for detection of various bacteria, such as Brucella spp. with a LOD of $10^{3}$ $\mathrm{CFU} / \mathrm{mL}$ in $10^{5}$ minutes. ${ }^{30}$ In our preliminary study, IMB-QDs were used for detection of B. pseudomallei in positive blood samples and found that the sensitivity of inoculated blood samples was $10^{4} \mathrm{CFU} / \mathrm{ml}$ when observed by the naked eye and was $10^{3} \mathrm{CFU} / \mathrm{ml}$ when detected with spectrofluorometry.

In conclusion, the IMB-ELISA was successfully developed for detecting B. pseudomallei in blood samples. Moreover, the 4B11-IMB developed could also be used to concentrate the bacteria in the clinical specimens. Although there are still some shortcomings of the kit, such as the lower sensitivity for detection of the low numbers of bacteria in the infected blood samples, it needed $6 \mathrm{~h}$ before getting the result, which is not a good test for rapid diagnosis. However, its advantage might be used for concentrating the bacteria and adapted for other samples such as sputum, urine or drinking water.

\section{Acknowledgments}

We would like to acknowledge financial support from the Faculty of Medicine and Melioidosis Research Center, Khon Kaen University. We would like to acknowledge Emeritus Professor James A. Will, University of Wisconsin-Madison, under Publication Clinic, KKU, Thailand for editing this manuscript.

\section{Conflict of interest}

None 


\section{Funding}

This work was supported by the Faculty of Medicine Research Grant Khon Kaen University (Grant number IN58240) Faculty of Medicine, Melioidosis Research Center, Khon Kaen University, Higher Education Research Promotion and National Research University Project of Thailand, CHE, through the Health Cluster (SheP-GMS) and National Research University Program (Grant number Ph.D. 54212)

\section{References}

1. Tiangpitayakorn C, Songsivilai S, Piyasangthong N, Dharakul T. Speed of detection of Burkholderia pseudomallei in blood cultures and its correlation with the clinical outcome. Am J Trop Med Hyg. 1997;57(1):96-9.

2. Cheng AC. Melioidosis: advances in diagnosis and treatment. Curr Opin Infect Dis. 2010;23:554-9.

3. Harris PN, Williams NL, Morris JL, Ketheesan N, Norton RE. Evidence of Burkholderia pseudomallei-specific immunity in patient sera persistently nonreactive by the indirect hemagglutination assay. Clin Vaccine Immunol. 2011;18(8):1288-91.

4. Wuthiekanun V, Desakorn V, Wongsuvan G, Amornchai P, Cheng AC, Maharjan B, et al. Rapid immunofluorescence microscopy for diagnosis of melioidosis. Clin Diagn Lab Immunol. 2005;12(4):555-6.

5. Tandhavanant S, Wongsuvan G, Wuthiekanun V, Teerawattanasook N, Day NP, Limmathurotsakul D, et al. Monoclonal antibody-based immunofluorescence microscopy for the rapid identification of Burkholderia pseudomallei in clinical specimens. Am J Trop Med Hyg. 2013;89(1):165-8

6. Chantratita N, Tandhavanant S, Wongsuvan G, Wuthiekanun V, Teerawattanasook N, Day NP, et al. Rapid detection of Burkholderia pseudomallei in blood cultures using a monoclonal antibody-based immunofluorescent assay. Am J Trop Med Hyg. 2013;89(5):971-2.

7. Samosornsuk N, Lulitanond A, Saenla N, Anuntagool N, Wongratanacheewin S, Sirisinha S. Short report: evaluation of a monoclonal antibody-based latex agglutination test for rapid diagnosis of septicemic melioidosis. Am J Trop Med Hyg. 1999;61(5):735-7.

8. Houghton RL, Reed DE, Hubbard MA, Dillon MJ, Chen H, Currie BJ, et al. Development of a prototype lateral flow immunoassay (LFI) for the rapid diagnosis of melioidosis. PLoS Negl Trop Dis. 2014;8(3):e2727.

9. Olsvik O, Popovic T, Skjerve E, Cudjoe KS, Hornes E, Ugelstad J, et al. Magnetic separation techniques in diagnostic microbiology. Clin Microbiol Rev. 1994;7(1):43-54.

10. Aloni-Grinstein R, Schuster O, Yitzhaki S, Aftalion M, Maoz S, Steinberger -Levy I, et al. Isolation of Francisella tularensis and Yersinia pestis from Blood Cultures by Plasma Purification and Immunomagnetic Separation Accelerates Antibiotic Susceptibility Determination. Front Microbiol. 2017;8:312.

11. Bicart-See A, Rottman M, Cartwright M, Seiler B, Gamini N, Rodas M, et al. Rapid Isolation of Staphylococcus aureus Pathogens from Infected Clinical Samples Using Magnetic Beads Coated with Fc-Mannose Binding Lectin. PLoS One. 2016;11(6):e0156287.

12. Liandris E, Gazouli M, Andreadou M, Sechi LA, Rosu V, Ikonomopoulos J. Detection of pathogenic mycobacteria based on functionalized quantum dots coupled with immunomagnetic separation. PLoS One. 2011;6(5): e20026.
13. Mansfield LP, Forsythe SJ. The detection of Salmonella using a combined immunomagnetic separation and ELISA end-detection procedure. Lett Appl Microbiol. 2000;31(4):279-83.

14. Wang Z, Yue T, Yuan Y, Cai R, Niu C, Guo C. Development and evaluation of an immunomagnetic separation-ELISA for the detection of Alicyclobacillus spp. in apple juice. Int J Food Microbiol. 2013;166(1):28-33.

15. Wang YK, Wang YC, Wang HA, Ji WH, Sun JH, Yan YX. An immunomagnetic-bead-based enzyme-linked immunosorbent assay for sensitive quantification of fumonisin B1. Food Control. 2014;40:41-5.

16. Anuntagool N, Panichakul T, Aramsri P, Sirisinha S. Shedding of lipopolysaccharide and $200-\mathrm{kDa}$ surface antigen during the in vitro growth of virulent Ara- and avirulent Ara $^{+}$Burkholderia pseudomallei. Acta Trop. 2000;74(2-3):221-8.

17. Dulsuk A, Paksanont S, Sangchankoom A, Ekchariyawat P, Phunpang $\mathrm{R}$, Jutrakul $\mathrm{Y}$, et al. Validation of a monoclonal antibody-based immunofluorescent assay to detect Burkholderia pseudomallei in blood cultures. Trans R Soc Trop Med Hyg. 2017;110(11):670-2.

18. Rugdech P, Anuntagool N, Sirisinha S. Monoclonal antibodies to Pseudomonas pseudomallei and their potential for diagnosis of melioidosis. Am J Trop Med Hyg. 1995;52(3):231-5.

19. Anuntagool N, Sirisinha S. Antigenic relatedness between Burkholderia pseudomallei and Burkholderia mallei. Microbiol Immunol. 2002;46(3): 143-50.

20. Chemicell: Covalent Coupling Procedure on SiMAG-Amine by Carbodiimide Method [internet]. Berlin: publisher unknown; 2018 [cited 2018 Jan 15]; [ 3 p.]. Available from: http://www.chemicell.com/products/ protocols/docs/SiMAG-Amine.pdf.

21. Cheng AC, O'Brien M, Freeman K, Lum G, Currie BJ. Indirect hemagglutination assay in patients with melioidosis in northern Australia. Am J Trop Med Hyg. 2006;74(2):330-4.

22. Wiersinga WJ, Currie BJ, Peacock SJ. Melioidosis. N Engl J Med. 2012; 367(11):1035-44.

23. Robertson G, Sorenson A, Govan B, Ketheesan N, Houghton R, Chen H, et al. Rapid diagnostics for melioidosis: a comparative study of a novel lateral flow antigen detection assay. J Med Microbiol. 2015;64(8):845-8.

24. Peeters M, Chung P, Lin H, Mortelmans K, Phe C, San C, et al. Diagnostic accuracy of the InBiOS AMD rapid diagnostic test for the detection of Burkholderia pseudomallei antigen in grown blood culture broth. Eur J Clin Microbiol Infect Dis. 2018;37(6):1169-77.

25. Yazdankhah SP, Solverod L, Simonsen S, Olsen E. Development and evaluation of an immunomagnetic separation-ELISA for the detection of Staphylococcus aureus thermostable nuclease in composite milk. Vet Microbiol. 1999;67(2):113-25.

26. Varshney M, Yang L, Su XL, Li Y. Magnetic nanoparticle-antibody conjugates for the separation of Escherichia coli O157:H7 in ground beef. J Food Prot. 2005;68(9):1804-11.

27. Huang H, Ruan C, Lin J, Li M, Cooney LM, Oliver WF, et al. Magnetic Nanoparticle Based Magnetophoresis for Efficient Separation of E. coli O157:H7. T ASABE. 2011;54(3):1015.

28. Hatcher CL, Muruato LA, Torres AG. Recent Advances in Burkholderia mallei and B. pseudomallei Research. Curr Trop Med Rep. 2015;2(2):62-9.

29. Chan WC, Nie S. Quantum dot bioconjugates for ultrasensitive nonisotopic detection. Science. 1998;281(5385):2016-8.

30. Song D, Qu X, Liu Y, Li L, Yin D, Li J, et al. A Rapid Detection Method of Brucella with Quantum Dots and Magnetic Beads Conjugated with Different Polyclonal Antibodies. Nanoscale Res Lett. 2017;12(1):179. 